\title{
Mereduksi Voice of Customer pada Pengembangan Produk Alat Pembuka Tutup Galon Menggunakan Analisis Faktor
}

\section{Reducing Voice of Customer in Product Development for Gallon Cap Opener Using Factor Analysis}

\author{
Glisina Dwinoor Rembulan ${ }^{1 *}$, Tony Wijaya ${ }^{1}$, Andrew Ruslie ${ }^{1}, J_{0 r d y}{ }^{1}$, Rama Adi Saputra \\ Sunadynatha ${ }^{1}$ \\ ${ }^{1}$ Program Studi Teknik Industri, Universitas Bunda Mulia, Jl. Lodan Raya No. 2 Ancol, Jakarta Utara 14430, \\ Indonesia
}

Diterima: 25 Mei, 2020 / Disetujui: 31 Juli, 2020

\begin{abstract}
Currently, bottled drinking water has become the main choice for Indonesians. The percentage of consumption of bottled drinking water by Indonesians in 2018 reached $36.28 \%$ and an increase in 2019 reached $38.25 \%$. One package that is often used is gallon packaging. There are several problems that people find when opening the gallon lid. The results of initial interviews with the community indicated that there were several problems, including the high risk of injury to the hands if you opened the gallon lid using a knife and the hands hurt if you opened the gallon cap manually without tools. These problems can be overcome by developing a product for a gallon cap opener that is tailored to customer needs or voice of customer (VOC). The method used in this research is factor analysis. A large number of community necessities make the product development process difficult because of the many needs that must be met. The purpose of this study was to reduce the number of VOCs. The Kaiser Meyer Olkin (KMO) test was used to see the suitability of the data used in factor analysis, while Bartlett's test was used to determine the significant correlation on each indicator. The result of factor analysis shows that 12 customer needs can be reduced to 3 customer needs, namely affordable gallon cap opening price, adjustable gallon cap opener diameter, and multifunctional gallon lid opener.
\end{abstract}

Keywords: Product development, Voice of Customer, Factor Analysis

\begin{abstract}
ABSTRAK
Saat ini air minum dalam kemasan telah menjadi pilihan utama oleh masyarakat Indonesia. Persentase konsumsi air minum dalam kemasan oleh masyarakat indonesia pada tahun 2018 mencapai 36,28\% dan mengalami peningkatan pada tahun 2019 mencapai $38,25 \%$. Salah satu kemasan yang sering digunakan adalah kemasan galon. Terdapat beberapa masalah yang ditemukan masyarakat saat membuka tutup galon. Hasil wawancara awal kepada masyarakat menunjukkan adanya beberapa masalah antara lain adanya risiko cedera yang tinggi pada tangan jika membuka tutup galon menggunakan pisau dan tangan terasa sakit jika membuka tutup galon secara manual tanpa alat bantu. Masalahmasalah tersebut dapat diatasi dengan melakukan pengembangan produk alat pembuka tutup galon yang disesuaikan dengan kebutuhan pelanggan atau voice of customer (VOC). Metode yang digunakan pada penelitian ini adalah analisis faktor. Banyaknya kebutuhan masyarakat membuat proses pengembangan produk mengalami kesulitan karena banyaknya kebutuhan yang harus dipenuhi. Tujuan penelitian ini adalah untuk mereduksi jumlah VOC. Uji Kaiser Meyer Olkin (KMO) digunakan untuk melihat kecocokan data yang digunakan dalam analisis faktor sedangkan uji Bartlett's digunakan untuk mengetahui korelasi yang signifikan pada setiap indikator. Hasil analisis faktor menunjukkan bahwa 12 kebutuhan pelanggan dapat direduksi menjadi 3 kebutuhan pelanggan yaitu harga pembuka tutup galon terjangkau, diameter alat pembuka tutup galon adjustable, dan alat pembuka tutup galon multifungsi.
\end{abstract}

Kata Kunci: Pengembangan produk, Voice of Customer, Analisis Faktor

*email: grembulan@bundamulia.ac.id 


\section{PENDAHULUAN}

Kebutuhan terhadap air menjadi salah satu kebutuhan primer yang harus dipenuhi. Air menjadi sumber utama bagi manusia dalam menjalankan aktivitas sehari-hari. Pentingnya kebutuhan air terhadap masyarakat membuat banyaknya industri di Indonesia yang bergerak pada sektor penjualan air minum dalam kemasan. Jumlah pelaku industri di sektor ini mencapai 700 perusahaan pada tahun 2019 (Rini, 2019). Pangsa pasar industri air minum dalam kemasan terhadap industri minuman mencapai $84 \%$ dan menyumbang 3,3\% terhadap produk domestik bruto (PDB) (Kementerian Perindustrian, 2019).

Air minum dalam kemasan saat ini telah menjadi pilihan utama oleh masyarakat Indonesia. Produksi nasional air minum dalam kemasan pada tahun 2019 sekitar 30 miliar liter (Sandi, 2020). Persentase konsumsi air minum dalam kemasan oleh masyarakat indonesia pada tahun 2018 mencapai $36,28 \%$ dan mengalami peningkatan pada tahun 2019 mencapai 38,25\% (Badan Pusat Statistik, 2019). Banyaknya masyarakat yang mengonsumsi air minum dalam kemasan berdampak terhadap penjualan air galon karena galon adalah salah satu kemasan yang banyak digunakan. Air dengan kemasan galon menjadi pilihan masyarakat karena dapat dilakukan pengisian kembali di pabrik sehingga lebih ramah lingkungan (Ramadhan, 2020). Selain itu air dalam kemasan galon lebih praktis dan menghemat waktu dibandingkan harus memasak air sendiri di rumah.

Seiring penggunaan air galon dalam kehidupan sehari-hari maka ditemukan beberapa masalah yang sering dihadapi. Hasil wawancara awal kepada masyarakat menunjukkan adanya beberapa masalah antara lain adanya risiko cedera yang tinggi pada tangan jika membuka tutup galon menggunakan pisau, tutup galon sering tidak terbuka semuanya jika menggunakan pisau, sulit membuka segel tutup galon jika menggunakan pisau, dan tangan terasa sakit jika membuka tutup galon secara manual tanpa alat bantu. Beberapa masalah yang dihadapi saat ini dapat diatasi dengan melakukan pengembangan produk alat pembuka tutup galon yang disesuaikan dengan kebutuhan pelanggan atau masyarakat sehingga diharapkan pada waktu yang akan datang dapat memberikan kemudahan saat membuka tutup galon.

Kebutuhan pelanggan atau lebih dikenal dengan VOC adalah bagian yang sangat penting dalam proses pengembangan produk karena pelanggan berperan penting saat perancangan suatu produk (Tannady, 2015). Informasi merupakan atribut penting yang harus diperhatikan dalam mencapai kepuasan pelanggan (Rowena, Wilujeng dan Rembulan, 2020). Pelanggan akan merasa puas jika penyedia jasa memahami hal yang diinginkan pelanggan (Wilujeng, Rembulan dan Regina, 2019). Di satu sisi, banyaknya kebutuhan masyarakat membuat proses pengembangan produk mengalami kesulitan karena banyaknya kebutuhan yang harus dipenuhi. Sementara di sisi lain, persepsi pelanggan terhadap produk diharapkan bersifat positif agar dampak yang baik secara berkelanjutan dapat tercipta (Rembulan, 2018). Berbagai keunggulan harus ditawarkan kepada pelanggan agar produk dapat terus bertahan dalam persaingan (Wilujeng et al., 2019). Salah satu cara untuk mereduksi kebutuhan pelanggan adalah dengan melakukan analisis faktor. Analisis faktor adalah sebuah prosedur utama yang digunakan untuk mereduksi dan meringkas data (Saini, Kumar dan Kaur, 2020). Beberapa penelitian yang menggunakan analisis faktor telah dilakukan pada konsumsi makanan organik (Sobhanifard, 2018), persepsi, motivasi dan sikap mahasiswa (Saini, Kumar dan Kaur, 2020), kriteria perumahan terjangkau (Zulkepli, Sipan dan Jibril, 2017), pengembangan indeks status kesehatan (Mohamad et al., 2018) dan program pembangunan ekonomi (Hamza, Musta'amal dan Kamin, 2019).

Penelitian ini menggunakan analisis faktor dengan metode rotasi varimax dengan tujuan mereduksi Voice of Customer (VOC) pada proses pengembangan produk alat pembuka tutup galon.

\section{TINJAUAN PUSTAKA}

\subsection{Voice of Customer (VOC)}

VOC adalah daftar kebutuhan dan keinginan pelanggan yang digunakan dalam proses pengembangan produk (Yustian, 2015). Selain untuk pengembangan produk, VOC juga digunakan untuk mendengarkan masukan, 
tanggapan, dan klaim dari setiap pelanggan yang telah melakukan pembelian produk atau jasa (Sachamanorom dan Senoo, 2016). Tujuan dari VOC yaitu menjadi proaktif dan inovatif dalam melihat perubahan kebutuhan pelanggan dari waktu ke waktu (Suwandi, 2016). Terdapat 2 prosedur umum yang digunakan dalam pengumpulan VOC yaitu menentukan atribut apa saja yang dianggap penting oleh konsumen dan mengukur tingkat kepentingan dari atribut-atribut tersebut (Utami, 2018). VOC dapat diperoleh melalui beberapa cara antara lain survei, wawancara, grup diskusi, dan metode serupa lainnya (Erdil dan Arani, 2018).

VOC adalah sesuatu yang sangat penting bagi perusahaan dan dapat membantu perusahaan untuk meningkatkan produk dan layanan mereka (Sachamanorom dan Senoo, 2016; Aguwa, Olya dan Monplaisir, 2017). Penentuan kebutuhan pelanggan yang akurat dan interpretasi yang tepat dapat memberikan kepuasan maksimal terhadap pelanggan (Aguwa, Olya dan Monplaisir, 2017). Kebutuhan pelanggan yang sering disebut "what" dapat diubah menjadi persyaratan teknis yang sering disebut "how" pada proses pengembangan produk (Erdil dan Arani, 2018).

\subsection{Analisis Faktor}

Analisis faktor adalah suatu teknik reduksi data statistik untuk menentukan konstruksi dasar yang overlap antar kuesioner (Bernstein dan Calamia, 2019). Analisis faktor adalah metode interdependen multivariat yang banyak digunakan dalam penelitian di bidang administrasi khususnya penelitian dengan tipe survei (Sobhanifard, 2018). Verifikasi data pada analisis faktor menggunakan uji Kaiser Meyer Olkin (KMO) Measure of Sampling Adequacy dan uji Bartlett's of sphericity (Zulkepli, Sipan dan Jibril, 2017). Uji KMO digunakan untuk melihat kecocokan data yang akan digunakan dalam analisis faktor sedangkan uji Bartlett's digunakan untuk mengetahui apakah terdapat korelasi yang signifikan pada setiap indikator (Luthfia et al., 2018). Suatu data dapat dilakukan analisis faktor apabila uji KMO memiliki nilai antara 0,5 hingga 1 dan uji Bartlett's memiliki tingkat signifikansi lebih kecil dari 0,5 (Watson, 2017; Fukimoto, Rodrigues dan Furtado, 2019).
Metode yang digunakan untuk mengetahui jumlah faktor yang terbentuk yaitu nilai eigenvalues dan analisis scree plot (Zulkepli, Sipan dan Jibril, 2017). Nilai eigenvalues harus memiliki nilai melebihi 1 sehingga dapat membentuk menjadi satu faktor (Zulkepli, Sipan dan Jibril, 2017). Metode rotasi pada analisis faktor dapat dilakukan dengan dua cara yaitu rotasi orthogonal dan rotasi oblique (Maskey, Fei dan Nguyen, 2018). Beberapa rotasi orthogonal yang paling umum digunakan adalah varimax, quartimax, dan equamax sedangkan pada rotasi oblique yaitu direct oblimin dan promax (Watson, 2017). Rotasi faktor dilakukan untuk mengelompokkan indikator ke setiap dimensi secara maksimal (Luthfia et al., 2018).

\section{METODOLOGI}

Jenis data yang digunakan dalam penelitian ini adalah data primer yang didapatkan secara langsung oleh peneliti. Pengumpulan data dilakukan melalui proses wawancara dan penyebaran kuesioner. Urutan tahap-tahap yang harus dilakukan dalam penelitian ini ditunjukkan pada diagram alir penelitian. Gambar 1 menunjukkan diagram alir dari penelitian. 


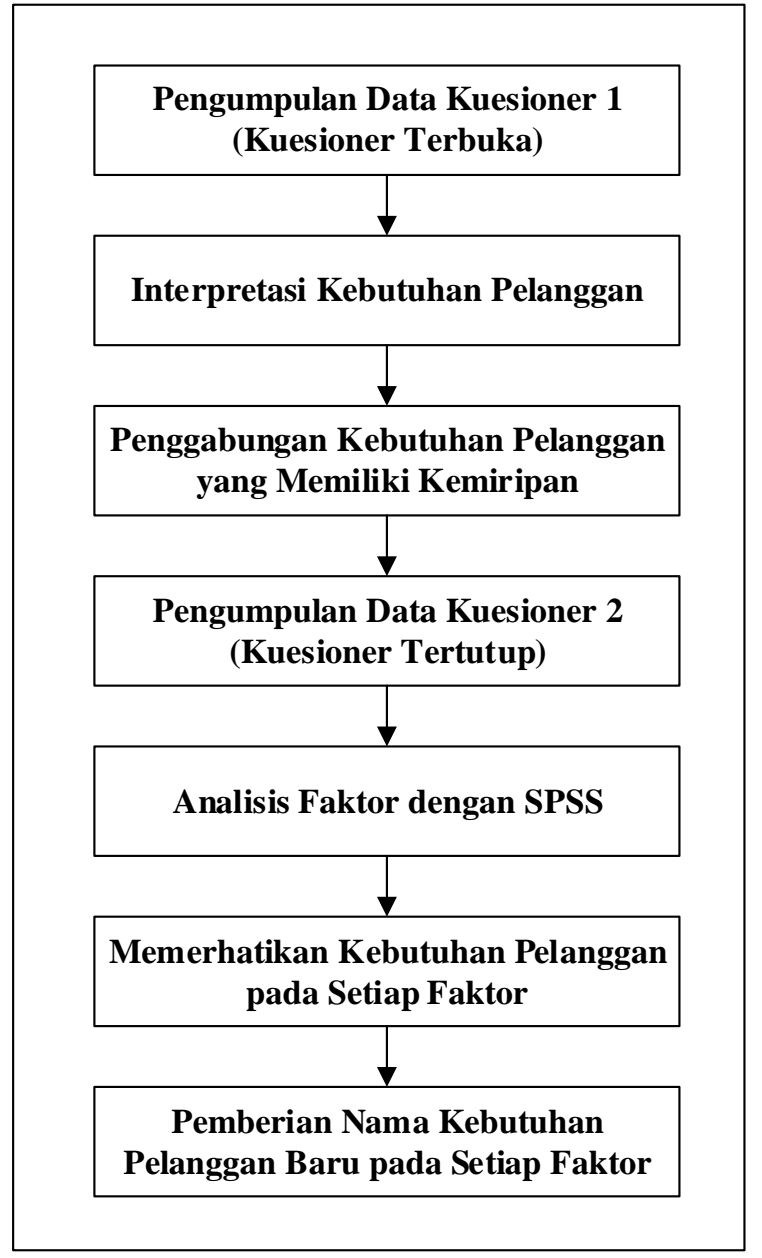

Gambar 1. Diagram Alir Penelitian

Gambar 1 menunjukkan bahwa terdapat 7 langkah yang dilakukan dalam penelitian antara lain:

1. Mengumpulkan data melalui kuesioner 1 (kuesioner terbuka). Kuesioner ini dilakukan melalui proses wawancara kepada pelanggan air galon yang terdiri dari 6 pertanyaan. Kuesioner ini mewakili persepsi konsumen terhadap produk (Rembulan, 2019).

2. Menginterpretasikan kebutuhan pelanggan. Interpretasi dilakukan berdasarkan jawaban pelanggan pada kuesioner 1 sehingga dapat mengetahui hal-hal apa yang dibutuhkan oleh pelanggan.

3. Menggabungkan kebutuhan pelanggan yang memiliki kemiripan. Kebutuhan pelanggan yang memiliki kemiripan akan digabungkan menjadi satu kebutuhan saja.
4. Mengumpulkan data melalui kuesioner 2 (kuesioner tertutup). Kuesioner ini disusun berdasarkan kebutuhan pelanggan yang telah didapatkan. Penilaiannya menggunakan skala likert dengan skor 1 hingga 5.

5. Melakukan analisis faktor dengan software SPSS. Analisis ini digunakan untuk mereduksi jumlah kebutuhan pelanggan atau VOC.

6. Memerhatikan kebutuhan pelanggan pada setiap faktor yang terbentuk. Kebutuhan pelanggan akan dikelompokkan pada faktornya masing-masing berdasarkan hasil analisis faktor.

7. Memberikan nama kebutuhan pelanggan baru pada setiap faktor. Penamaan dapat dilakukan dengan cara menggabungkan nama kebutuhan pelanggan atau mengambil kebutuhan pelanggan dengan skor korelasi tertinggi pada rotated component matrix.

\section{HASIL DAN PEMBAHASAN}

\subsection{Kuesioner 1 (Kuesioner Terbuka)}

Pengumpulan data pada tahap ini dilakukan melalui proses wawancara kepada pelanggan air galon sehingga dapat mengetahui kebutuhan dan permasalahan yang sedang dihadapi. Wawancara dilakukan dengan memberikan beberapa pertanyaan. Tabel 1 menunjukkan pertanyaan yang digunakan pada kuesioner 1 (kuesioner terbuka).

Berdasarkan Tabel 1 dapat dilihat bahwa terdapat 6 pertanyaan yang digunakan dalam proses wawancara. Hal utama yang ingin diketahui pada tahap ini adalah alat yang digunakan, hal yang disukai dari produk saat ini, hal yang tidak disukai dari produk saat ini, dan perbaikan apa yang diinginkan untuk pengembangan produk alat pembuka tutup galon.

Tabel 1. Pertanyaan Kuesioner 1 (Kuesioner Terbuka)

\begin{tabular}{cl}
\hline No & \multicolumn{1}{c}{ Pertanyaan } \\
\hline $\mathbf{1}$ & $\begin{array}{l}\text { Alat apa yang sering anda gunakan untuk } \\
\text { membuka galon? }\end{array}$ \\
$\mathbf{2}$ & $\begin{array}{l}\text { Apa yang anda suka dengan alat pembuka } \\
\text { tutup galon saat ini? }\end{array}$ \\
$\mathbf{3}$ & $\begin{array}{l}\text { Apa yang anda tidak suka dengan alat } \\
\text { pembuka tutup galon saat ini? }\end{array}$ \\
\hline
\end{tabular}




\begin{tabular}{cl}
\hline No & \multicolumn{1}{c}{ Pertanyaan } \\
\hline $\mathbf{4}$ & $\begin{array}{l}\text { Apakah anda setuju jika dilakukan } \\
\text { pengembangan produk alat pembuka tutup } \\
\text { galon? }\end{array}$ \\
$\mathbf{5} \quad \begin{array}{l}\text { Perbaikan apa yang anda inginkan dari alat } \\
\text { pembuka tutup galon? (Warna, bentuk, } \\
\text { material dan ukuran) }\end{array}$ \\
$\mathbf{6} \quad \begin{array}{l}\text { Berapa kisaran harga alat pembuka tutup } \\
\text { galon yang diinginkan setelah dilakukan } \\
\text { pengembangan produk? }\end{array}$ \\
\hline
\end{tabular}

Tabel 2. Daftar Kebutuhan Pelanggan

\begin{tabular}{|c|c|}
\hline No & Kebutuhan Pelanggan \\
\hline 1 & $\begin{array}{l}\text { Alat pembuka tutup galon yang dapat } \\
\text { digunakan dengan mudah oleh semua orang. }\end{array}$ \\
\hline 2 & $\begin{array}{l}\text { Alat pembuka tutup galon yang dapat } \\
\text { membuka segel galon dengan mudah. }\end{array}$ \\
\hline 3 & $\begin{array}{l}\text { Alat pembuka tutup galon yang dapat } \\
\text { mengangkat tutup galon dengan mudah } \\
\text { setelah segelnya dibuka. }\end{array}$ \\
\hline 4 & $\begin{array}{l}\text { Alat pembuka tutup galon yang dapat } \\
\text { digunakan dengan aman oleh semua orang. }\end{array}$ \\
\hline 5 & $\begin{array}{l}\text { Alat pembuka tutup galon yang dapat } \\
\text { mengurangi resiko cidera saat membuka tutup } \\
\text { galon. }\end{array}$ \\
\hline 6 & $\begin{array}{l}\text { Alat pembuka tutup galon memiliki pegangan } \\
\text { yang tidak licin. }\end{array}$ \\
\hline 7 & $\begin{array}{l}\text { Alat pembuka tutup galon memiliki fitur } \\
\text { tambahan. }\end{array}$ \\
\hline 8 & $\begin{array}{l}\text { Alat pembuka tutup galon terbuat dari } \\
\text { material yang aman, ringan, dan tahan lama. }\end{array}$ \\
\hline 9 & $\begin{array}{l}\text { Alat pembuka tutup galon memiliki bentuk } \\
\text { yang sesuai dengan tutup galon. }\end{array}$ \\
\hline 10 & $\begin{array}{l}\text { Alat pembuka tutup galon memiliki bentuk } \\
\text { dengan diameter yang adjustable. }\end{array}$ \\
\hline 11 & $\begin{array}{l}\text { Alat pembuka tutup galon memiliki warna } \\
\text { yang cerah. }\end{array}$ \\
\hline 12 & $\begin{array}{l}\text { Alat pembuka tutup galon memiliki harga } \\
\text { yang terjangkau. }\end{array}$ \\
\hline
\end{tabular}

\subsection{Hasil Voice of Customer (VOC)}

Kebutuhan pelanggan atau lebih dikenal dengan VOC adalah hasil interpretasi dari proses wawancara yang telah dilakukan. Kebutuhan pelanggan yang memiliki kemiripan akan digabungkan menjadi 1 kebutuhan saja. Tabel 2 menunjukkan daftar kebutuhan pelanggan.
Berdasarkan Tabel 2 dapat dilihat bahwa terdapat 12 kebutuhan pelanggan setelah dilakukan proses penggabungan kebutuhan pelanggan yang mirip. 12 kebutuhan pelanggan ini akan dijadikan pertanyaan pada kuesioner 2 .

\subsection{Kuesioner 2 (Kuesioner Tertutup)}

Pertanyaan yang digunakan pada kusioner 2 berdasarkan kebutuhan pelanggan yang telah digabungkan. Data dikumpulkan dengan cara menyebarkan kuesioner dan penilaiannya menggunakan skala likert dari skor 1 hingga 5 (sangat tidak penting, tidak penting, cukup penting, penting, sangat penting). Tabel 3 menunjukkan pertanyaan pada kuesioner 2 (kuesioner tertutup).

Berdasarkan Tabel 3 dapat dilihat bahwa terdapat 12 pertanyaan yang akan disebarkan kepada pelanggan. Setiap pelanggan akan menjawab sesuai tingkat kepentingan mereka masing-masing terhadap kebutuhan pelanggan.

\subsection{Hasil Analisis Faktor}

Jumlah kebutuhan pelanggan yang banyak akan direduksi menggunakan analisis faktor. Tujuan analisis ini dilakukan yaitu untuk menggabungkan kebutuhan pelanggan yang memiliki korelasi menjadi 1 faktor sehingga jumlah kebutuhan pelanggan akan menjadi lebih sedikit. Hal ini dapat memudahkan dalam proses pengembangan produk yang akan dilakukan. Tahap pertama dari analisis faktor yaitu melihat apakah data yang akan digunakan telah memenuhi syarat nilai Kaiser Meyer Olkin (KMO) dan Bartlett's of sphericity. Tabel 4 menunjukkan hasil uji KMO dan uji Bartlett's of sphericity.

Berdasarkan Tabel 4 dapat dilihat bahwa nilai KMO yaitu 0,807 dan nilai signifikansi Bartlett's of sphericity yaitu 0,000 sehingga dapat dikatakan data telah memenuhi syarat. Setelah itu dilanjutkan dengan melihat nilai anti-image matrices apakah telah memenuhi syarat Measures of Sampling Adequacy (MSA). Tabel 5 menunjukkan hasil anti-image matrices. 
Tabel 3. Pertanyaan Kuesioner 2 (Kuesioner Tertutup)

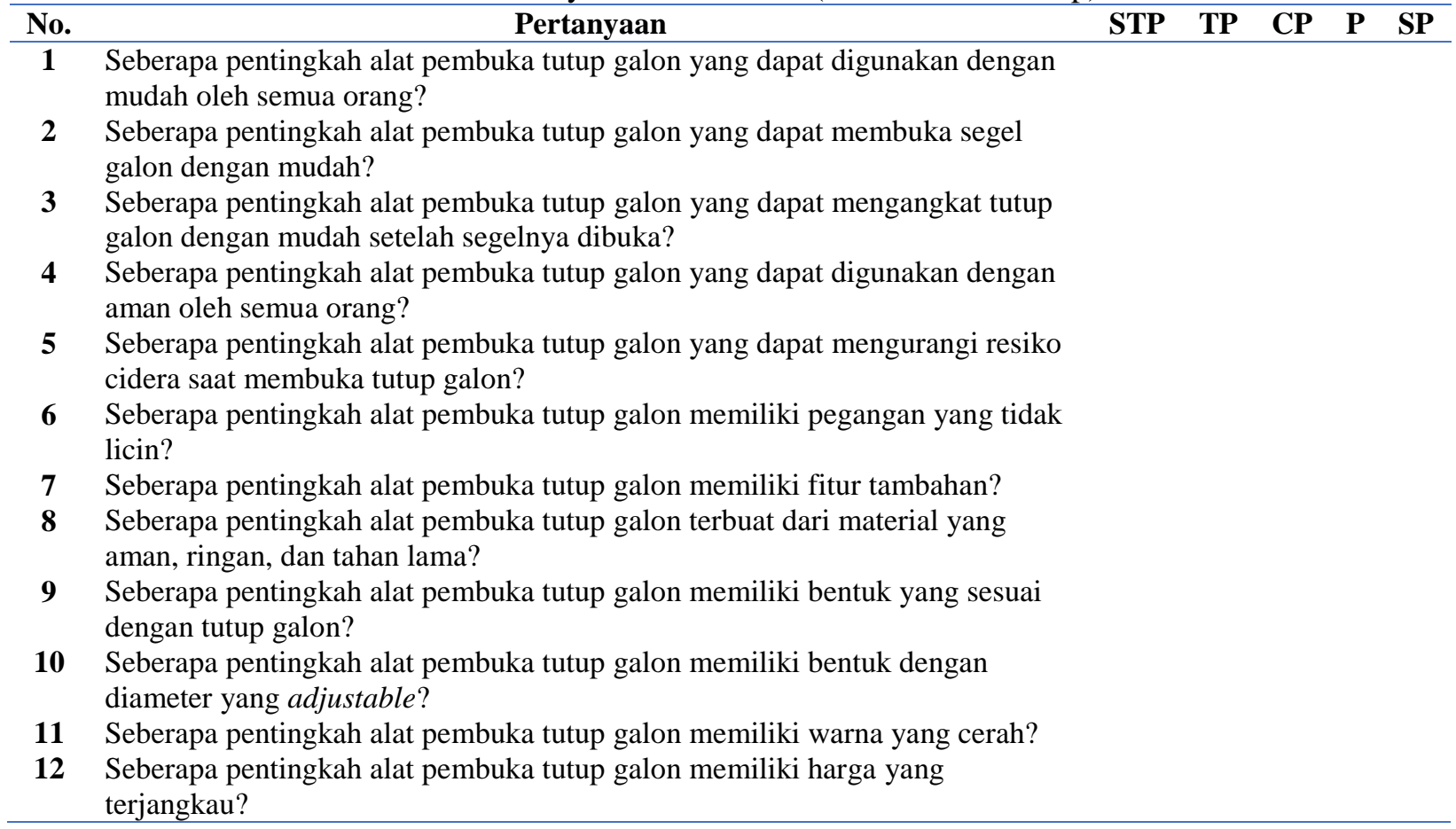


Tabel 4. Uji KMO dan Uji Bartlett's of Sphericity Ke-1

\begin{tabular}{lr}
\hline & KMO and Bartlett's Test \\
\hline Kaiser-Meyer-Olkin Measure of Sampling Adequacy & \\
\hline Bartlett's Test of Sphericity & Approx. Chi-Square \\
& $d f \quad$ Sig. \\
& 243,708 \\
& 66 \\
\hline
\end{tabular}

\begin{tabular}{|c|c|c|c|c|c|c|c|c|c|c|c|c|}
\hline Need 1 & $0.830^{\mathrm{a}}$ & -0053 & -0.271 & - 350 & 0059 & & & & & & & \\
\hline Need 2 & $-0,053$ & $0,788^{a}$ & $-0,308$ & -0.152 & $-0,078$ & -0151 & 361 & 173 مـ & 0196 & 0105 & 0123 & 0263 \\
\hline Need 3 & $-0,271$ & $-0,308$ & $0,825^{\mathrm{a}}$ & 0,042 & 0,048 & $-0,181$ & $-0,087$ & 0,085 & 0,095 & 0,005 & $-0,087$ & $-0,197$ \\
\hline Need 4 & $-0,350$ & $-0,152$ & 0,042 & $0,797^{\mathrm{a}}$ & $-0,619$ & $-0,187$ & 0,205 & $-0,115$ & 0,059 & $-0,043$ & 0,032 & 0,007 \\
\hline Need 5 & 0,059 & $-0,078$ & 0,048 & $-0,619$ & $0,805^{\mathrm{a}}$ & 0,118 & $-0,199$ & $-0,006$ & $-0,078$ & $-0,027$ & $-0,085$ & $-0,217$ \\
\hline Need 6 & 0,175 & $-0,151$ & $-0,181$ & $-0,187$ & 0,118 & $0,838^{a}$ & 0,049 & $-0,203$ & $-0,139$ & $-0,385$ & $-0,006$ & 0,035 \\
\hline Need 7 & 0,115 & $-0,361$ & $-0,087$ & 0,205 & $-0,199$ & 0,049 & $0,740^{\mathrm{a}}$ & $-0,134$ & $-0,304$ & $-0,069$ & $-0,281$ & $-0,040$ \\
\hline Need 8 & $-0,210$ & $-0,173$ & 0,085 & $-0,115$ & $-0,006$ & $-0,203$ & $-0,134$ & $0,894^{\mathrm{a}}$ & $-0,033$ & $-0,216$ & 0,177 & $-0,218$ \\
\hline Need 9 & $-0,101$ & 0,196 & 0,095 & 0,059 & $-0,078$ & $-0,139$ & $-0,304$ & $-0,033$ & $0,791^{\mathrm{a}}$ & $-0,257$ & $-0,009$ & 0,023 \\
\hline Need 10 & $-0,088$ & 0,105 & 0,005 & $-0,043$ & $-0,027$ & $-0,385$ & $-0,069$ & $-0,216$ & $-0,257$ & $0,867^{\mathrm{a}}$ & $-0,028$ & 0,040 \\
\hline Need 11 & $-0,280$ & 0,123 & $-0,087$ & 0,032 & $-0,085$ & $-0,006$ & $-0,281$ & 0,177 & $-0,009$ & $-0,028$ & $0,485^{\mathrm{a}}$ & 0,303 \\
\hline Need 12 & $-0,142$ & 0,263 & $-0,197$ & 0,007 & $-0,217$ & 0,035 & $-0,040$ & $-0,218$ & 0,023 & 0,040 & 0,303 & $0,711^{\mathrm{a}}$ \\
\hline
\end{tabular}


Tabel 6. Uji KMO dan Uji Bartlett's of Sphericity Ke-2

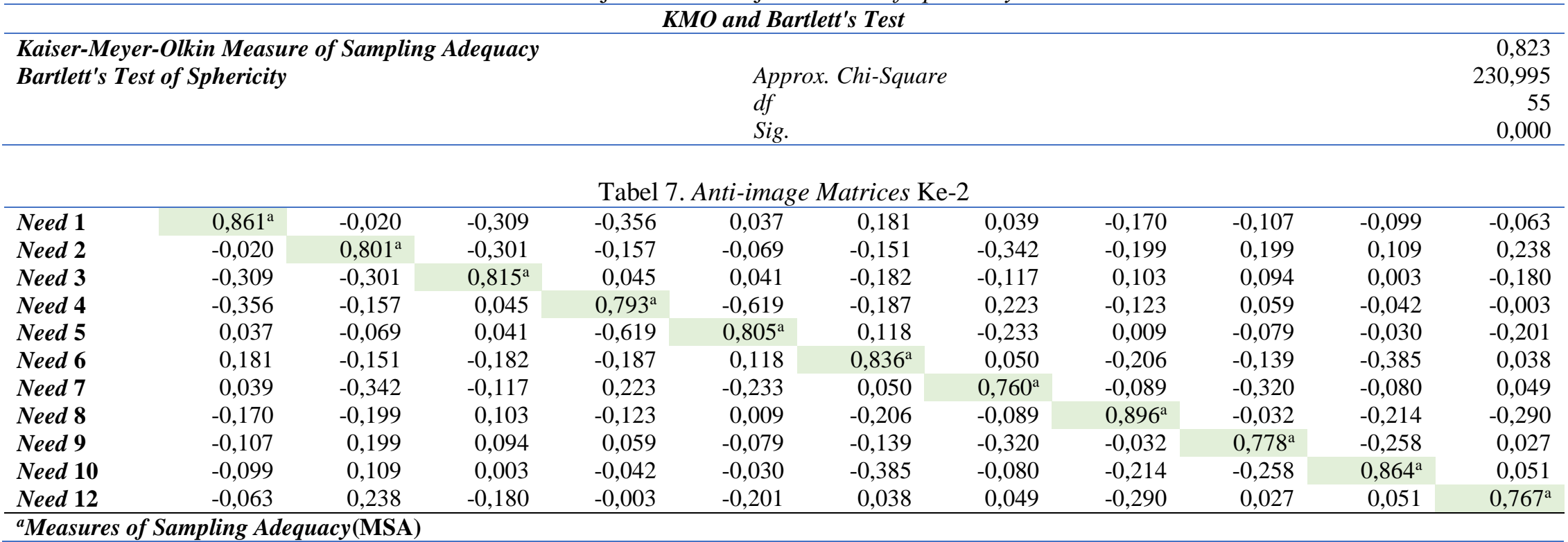


Berdasarkan Tabel 5 dapat dilihat bahwa semua kebutuhan memiliki nilai MSA >0,5 kecuali kebutuhan 11 karena memiliki nilai 0,485. Oleh karena itu dilakukan analisis faktor kembali tanpa mengikutsertakan kebutuhan 11. Tabel 6 berikut menunjukkan hasil uji KMO dan Bartlett's of sphericity tanpa mengikutsertakan kebutuhan 11.

Berdasarkan Tabel 6 dapat dilihat bahwa analisis faktor ke-2 memiliki nilai KMO yaitu 0,823 dan nilai signifikansi Bartlett's of sphericity yaitu 0,000 sehingga dapat dikatakan telah memenuhi syarat. Setelah itu melihat kembali nilai anti-image matrices apakah telah memenuhi syarat MSA. Tabel 7 menunjukkan hasil antiimage matrices tanpa mengikutsertakan kebutuhan 11.

Berdasarkan Tabel 7 dapat dilihat bahwa semua kebutuhan memiliki nilai MSA $>0,5$. Oleh karena itu semua kebutuhan telah memenuhi syarat MSA dan tidak perlu lagi melakukan pengeluaran data. Selanjutnya melihat nilai communalities yang dihasilkan. Nilai communalities menjelaskan seberapa besar variabel dapat menjelaskan faktor. Tabel 8 menunjukkan nilai communalities setiap kebutuhan pelanggan.

Tabel 8. Nilai Communalities

\begin{tabular}{lrr} 
& Initial & Extraction \\
\hline Need 1 & 1,000 & 0,621 \\
Need 2 & 1,000 & 0,792 \\
Need 3 & 1,000 & 0,603 \\
Need 4 & 1,000 & 0,756 \\
Need 5 & 1,000 & 0,639 \\
Need 6 & 1,000 & 0,580 \\
Need 7 & 1,000 & 0,596 \\
Need 8 & 1,000 & 0,668 \\
Need 9 & 1,000 & 0,726 \\
Need 10 & 1,000 & 0,710 \\
Need 12 & 1,000 & 0,616
\end{tabular}

Berdasarkan Tabel 8 dapat dilihat bahwa nilai communalities dari setiap kebutuhan memiliki nilai $>0,5$. Hal ini dapat diartikan bahwa semua kebutuhan pelanggan dapat menjelaskan faktor lebih dari 50\%. Setelah itu dilanjutkan dengan melihat jumlah faktor yang terbentuk dari analisis faktor. Jumlah faktor yang terbentuk dapat dilihat pada total variance explained. Tabel 9 menunjukkan total variance explained.

Berdasarkan Tabel 9 dapat dilihat bahwa terdapat 11 komponen yang dianalisis. Jumlah faktor yang dapat terbentuk yaitu sebanyak 3 . Komponen 1 memiliki nilai eigenvalue $>1$ yaitu 4,925 maka disebut faktor 1 dan dapat menjelaskan $44,774 \%$ variasi. Komponen 2 memiliki nilai eigenvalue $>1$ yaitu 1,277 maka disebut faktor 2 dan dapat menjelaskan 11,612\% variasi. Komponen 3 memiliki nilai eigenvalue $>1$ yaitu 1,104 maka disebut faktor 3 dan dapat menjelaskan 10,037\% variasi. Apabila faktor 1,2, dan 3 dijumlahkan maka dapat menjelaskan $66,423 \%$ variasi. Selain melihat total variance explained, jumlah faktor yang terbentuk dapat dilihat juga pada gambar scree plot. Gambar 1 menunjukkan scree plot.

Berdasarkan Gambar 1 dapat dilihat bahwa terdapat 3 faktor yang terbentuk karena memiliki nilai eigenvalue $>1$. Setelah mengetahui jumlah faktor yang terbentuk maka dilanjutkan dengan melihat setiap kebutuhan pelanggan masuk ke dalam faktor yang mana. Kebutuhan pelangan pada setiap faktor dapat dilihat dari rotated component matrix. Metode rotasi yang digunakan adalah varimax. Rotasi ini cocok untuk data yang saling berkorelasi dan nilai pemuatan faktor diterima (Hamza, Musta'amal dan Kamin, 2019). Tabel 10 menunjukkan hasil rotated component matrix.

Tabel 9. Total Variance Explained

\begin{tabular}{|c|c|c|c|c|c|c|c|c|c|}
\hline \multirow{2}{*}{ Component } & \multicolumn{3}{|c|}{ Initial Eigenvalues } & \multicolumn{3}{|c|}{$\begin{array}{c}\text { Extraction Sums of Squared } \\
\text { Loadings }\end{array}$} & \multicolumn{3}{|c|}{$\begin{array}{c}\text { Rotation Sums of Squared } \\
\text { Loadings }\end{array}$} \\
\hline & Total & $\begin{array}{c}\% \text { of } \\
\text { Variance }\end{array}$ & $\begin{array}{c}\text { Cumulative } \\
\%\end{array}$ & Total & $\begin{array}{c}\text { \% of } \\
\text { Variance }\end{array}$ & $\begin{array}{c}\text { Cumulative } \\
\%\end{array}$ & Total & $\begin{array}{c}\text { \% of } \\
\text { Variance }\end{array}$ & $\begin{array}{c}\text { Cumulative } \\
\%\end{array}$ \\
\hline 1 & 4,925 & 44,774 & 44,774 & 4,925 & 44,774 & 44,774 & 2,733 & 24,844 & 24,844 \\
\hline 2 & 1,277 & 11,612 & 56,386 & 1,277 & 11,612 & 56,386 & 2,352 & 21,384 & 46,228 \\
\hline 3 & 1,104 & 10,037 & 66,423 & 1,104 & 10,037 & 66,423 & 2,222 & 20,196 & 66,423 \\
\hline 4 & 0,794 & 7,222 & 73,646 & & & & & & \\
\hline 5 & 0,741 & 6,735 & 80,381 & & & & & & \\
\hline
\end{tabular}




\begin{tabular}{|c|c|c|c|c|c|c|c|c|c|}
\hline \multirow{2}{*}{ Component } & \multicolumn{3}{|c|}{ Initial Eigenvalues } & \multicolumn{3}{|c|}{$\begin{array}{c}\text { Extraction Sums of Squared } \\
\text { Loadings }\end{array}$} & \multicolumn{3}{|c|}{$\begin{array}{c}\text { Rotation Sums of Squared } \\
\text { Loadings }\end{array}$} \\
\hline & Total & $\begin{array}{c}\% \text { of } \\
\text { Variance }\end{array}$ & $\begin{array}{c}\text { Cumulative } \\
\%\end{array}$ & Total & $\begin{array}{c}\% \text { of } \\
\text { Variance }\end{array}$ & $\begin{array}{c}\text { Cumulative } \\
\%\end{array}$ & Total & $\begin{array}{c}\% \text { of } \\
\text { Variance }\end{array}$ & $\begin{array}{c}\text { Cumulative } \\
\%\end{array}$ \\
\hline 6 & 0,603 & 5,481 & 85,862 & & & & & & \\
\hline 7 & 0,446 & 4,059 & 89,921 & & & & & & \\
\hline 8 & 0,371 & 3,373 & 93,294 & & & & & & \\
\hline 9 & 0,291 & 2,645 & 95,939 & & & & & & \\
\hline 10 & 0,278 & 2,531 & 98,470 & & & & & & \\
\hline 11 & 0,168 & 1,530 & 100,000 & & & & & & \\
\hline
\end{tabular}

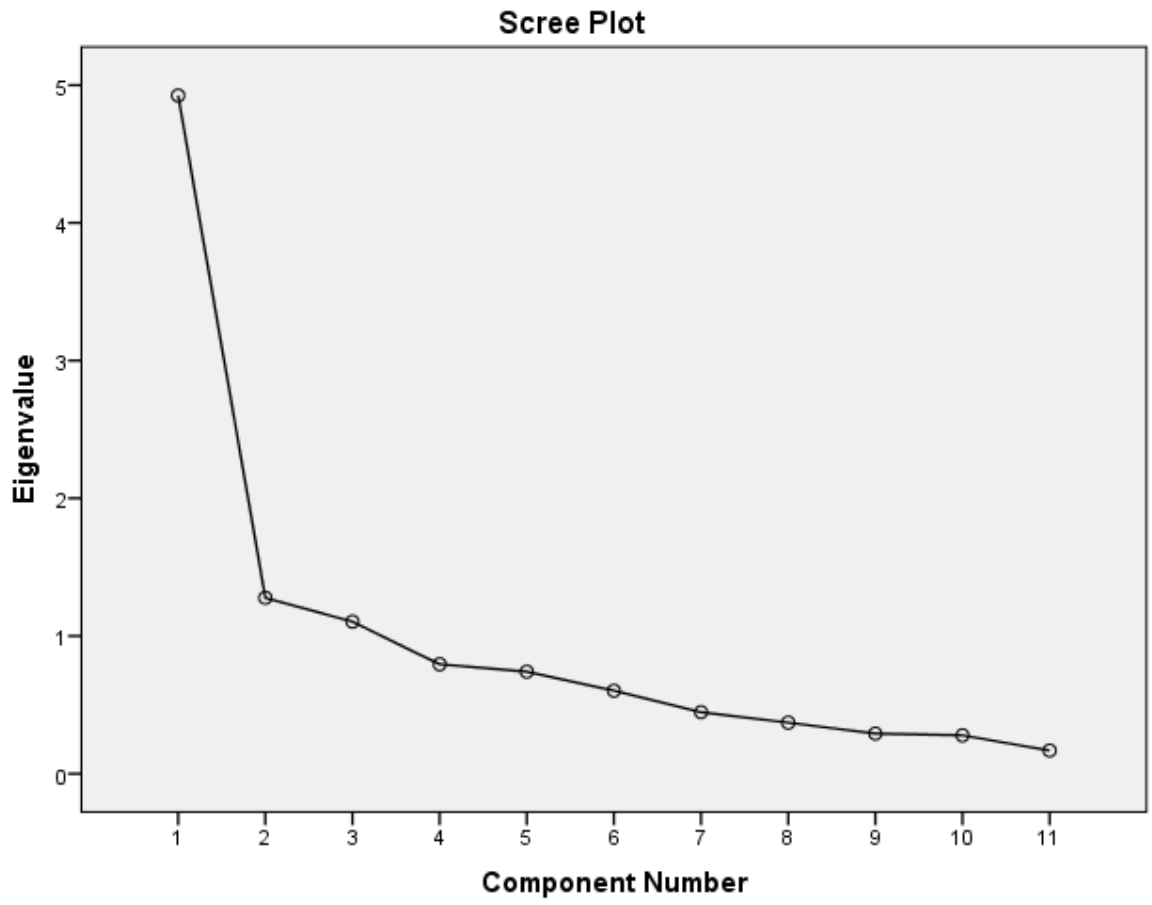

Gambar 1. Scree Plot

Tabel 10. Rotated Component Matrix

\begin{tabular}{lccc}
\hline & $\mathbf{1}$ & $\mathbf{2}$ & $\mathbf{3}$ \\
\hline Need 12 & 0,775 & 0,031 & $-0,121$ \\
Need 4 & 0,754 & 0,228 & 0,367 \\
Need 5 & 0,686 & 0,252 & 0,324 \\
Need 1 & 0,666 & 0,178 & 0,381 \\
Need 8 & 0,580 & 0,478 & 0,321 \\
Need 9 & 0,079 & 0,847 & $-0,055$ \\
Need 10 & 0,327 & 0,761 & 0,158 \\
Need 6 & 0,269 & 0,618 & 0,354 \\
Need 2 & 0,189 & 0,146 & 0,857 \\
Need 3 & 0,297 & 0,031 & 0,717 \\
Need 7 & $-0,058$ & 0,524 & 0,563 \\
\hline Extraction Method: Principal Component \\
Analysis. \\
Rotation Method: Varimax with Kaiser \\
Normalization. \\
a. Rotation converged in 5 iterations. \\
\hline
\end{tabular}

Berdasarkan Tabel 10 dapat dilihat nilai korelasi setiap kebutuhan pelanggan. Penentuan masuk ke faktor yang mana dapat dilihat berdasarkan nilai korelasi terbesar. Kebutuhan 12, 4, 5, 1, dan 8 masuk ke faktor 1 karena memiliki nilai terbesar di faktor 1. Kebutuhan 9, 10, dan 6 masuk ke faktor 2 karena memiliki nilai terbesar di faktor 2. Kebutuhan 2, 3, dan 7 masuk ke faktor 3 karena memiliki nilai terbesar di faktor 3 . Tabel 11 menunjukkan kebutuhan pelanggan pada setiap faktor. 
Versi Online:

http://journal.ubm.ac.id/index.php/jiems

DOI: 10.30813/jiems.v13i2.2281

Hasil Penelitian

Tabel 11. Kebutuhan Pelanggan pada Setiap Faktor

\begin{tabular}{cl}
\hline Faktor & \multicolumn{1}{c}{ Kebutuhan Pelanggan } \\
\hline $\mathbf{1}$ & Alat pembuka tutup galon memiliki harga \\
& yang terjangkau. \\
& Alat pembuka tutup galon yang dapat \\
& digunakan dengan aman oleh semua \\
& orang. \\
& Alat pembuka tutup galon yang dapat \\
& mengurangi resiko cidera saat membuka \\
& tutup galon. \\
& Alat pembuka tutup galon yang dapat \\
& digunakan dengan mudah oleh semua \\
& orang. \\
& Alat pembuka tutup galon terbuat dari \\
& material yang aman, ringan, dan tahan \\
& lama. \\
\hline Alat pembuka tutup galon memiliki \\
bentuk yang sesuai dengan tutup galon. \\
Alat pembuka tutup galon memiliki \\
bentuk dengan diameter yang adjustable. \\
Alat pembuka tutup galon memiliki \\
pegangan yang tidak licin. \\
Alat pembuka tutup galon yang dapat \\
membuka segel galon dengan mudah. \\
Alat pembuka tutup galon yang dapat \\
mengangkat tutup galon dengan mudah \\
setelah segelnya dibuka. \\
Alat pembuka tutup galon memiliki fitur \\
tambahan.
\end{tabular}

Berdasarkan Tabel 11 dapat dilihat bahwa faktor 1 terdiri dari 5 kebutuhan pelanggan, faktor 2 terdiri dari 3 kebutuhan pelanggan, dan faktor 3 terdiri dari 3 kebutuhan pelanggan. Langkah terakhir adalah memberikan nama kebutuhan pelanggan baru pada setiap faktor. Tabel 11 menunjukkan nama kebutuhan pelanggan baru setiap faktor.

Tabel 12. Nama Kebutuhan Pelanggan Baru Setiap Faktor

\begin{tabular}{cl}
\hline Faktor & \multicolumn{1}{c}{ Nama Kebutuhan Pelanggan Baru } \\
\hline $\mathbf{1}$ & Harga pembuka tutup galon terjangkau. \\
$\mathbf{2}$ & $\begin{array}{l}\text { Diameter alat pembuka tutup galon } \\
\text { adjustable. }\end{array}$ \\
$\mathbf{3}$ & Alat pembuka tutup galon multifungsi. \\
\hline
\end{tabular}

Berdasarkan Tabel 12 dapat dilihat nama kebutuhan pelanggan baru yaitu harga pembuka tutup galon terjangkau, diameter alat pembuka tutup galon adjustable, dan alat pembuka tutup galon multifungsi. Hasil analisis faktor menunjukkan bahwa 12 kebutuhan pelanggan dapat direduksi menjadi 3 kebutuhan pelanggan. Ketiga kebutuhan pelanggan ini yang akan menjadi VOC di pengembangan produk yang akan datang.

\section{SIMPULAN}

Kebutuhan pelanggan atau yang dikenal dengan VOC adalah hal yang sangat penting diperhatikan pada proses pengembangan produk. Hasil analisis faktor menunjukkan 12 kebutuhan pelanggan direduksi menjadi 3 kebutuhan pelanggan yaitu harga pembuka tutup galon terjangkau, diameter alat pembuka tutup galon adjustable, dan alat pembuka tutup galon multifungsi. Harga pembuka tutup galon terjangkau dapat menjelaskan $44,774 \%$ variasi, diameter alat pembuka tutup galon adjustable dapat menjelaskan $11,612 \%$ variasi dan alat pembuka tutup galon multifungsi dapat menjelaskan 10,037\% variasi. Ketiga kebutuhan pelanggan apabila dijumlahkan dapat menjelaskan 66,423\% variasi.

Penelitian selanjutnya dapat memanfaatkan House of Quality (HOQ) yang mampu menggambarkan VOC dalam usulan produk (Wilujeng dan Rembulan, 2019). Produk dengan kualitas yang baik harus mampu menjawab kebutuhan pelanggan sekaligus dengan biaya yang dapat ditekan (Regina, Luin dan Rembulan, 2020). Oleh karena itu, penelitian selanjutnya dapat mempertimbangkan faktor biaya ke dalam perancangan produk. Produk bisa jadi hanya mengeluarkan sedikit uang namun tetap memiliki bobot yang signifikan (Wilujeng, Suyoto dan Rembulan, 2019). Maka dari itu, biaya perlu diminimalkan demi optimalisasi kinerja (Rembulan et al., 2020).

\section{DAFTAR PUSTAKA}

Aguwa, C., Olya, M. H. dan Monplaisir, L. (2017) "Modeling of Fuzzy Based Voice of Customer for Business Decision Analytics," Knowledge Based Systems, 125, hal. 136-145. doi: 10.1016/j.knosys.2017.03.019.

Badan Pusat Statistik (2019) Distribusi Persentase Rumah Tangga Menurut Provinsi dan Sumber Air Minum 2019. 
Tersedia

pada:

https://www.bps.go.id/indikator/indikator/ view_data_pub/0000/api_pub/100/da_04/1 (Diakses: 18 Mei 2020).

Bernstein, J. P. K. dan Calamia, M. (2019) "Dimensions of Driving Related Emotions and Behaviors: An Exploratory Factor Analysis of Common Self Report Measures," Accident Analysis and Prevention, 124, hal. 85-91. doi: 10.1016/j.aap.2019.01.004.

Erdil, N. O. dan Arani, O. M. (2018) "Quality Function Deployment: More than A Design Tool," International Journal of Quality and Service Sciences, 11(2), hal. 142-166. doi: 10.1108/IJQSS-02-2018-0008.

Fukimoto, N., Rodrigues, A. B. H. dan Furtado, O. M. (2019) "Modified Meet Your Match Felineality Validity Assessment: An exploratory Factor Analysis of A Sample of Domestic Cats in A Brazilian Shelter," Applied Animal Behaviour Science, 215, hal. 61-67. doi: 10.1016/j.applanim.2019.03.013.

Hamza, S., Musta'amal, A. H. Bin dan Kamin, Y. Bin (2019) "Exploratory Factor Analysis of Green Innovative Skill Elements in Building Construction Programme for Economic Sustainability," International Journal of Recent Technology and Engineering, 8(1C2), hal. 465-473.

Kementerian Perindustrian (2019) Investasi Mengalir di Bisnis Air Minum. Tersedia pada:

https://kemenperin.go.id/artikel/20136/Inv estasi-Mengalir-di-Bisnis-Air-Minum (Diakses: 18 Mei 2020).

Luthfia, A. et al. (2018) "Analisis Faktor Eksploratori Konstruk Risiko Online," Warta Ikatan Sarjana Komunikasi Indonesia, 1(1), hal. 63-70. doi: 10.25008/wartaiski.v1i01.9.

Maskey, R., Fei, J. dan Nguyen, H. O. (2018) “Use of Exploratory Factor Analysis in Maritime Research," Asian Journal of Shipping and Logistics, 34(2), hal. 91-111. doi: 10.1016/j.ajsl.2018.06.006.

Mohamad, M. et al. (2018) "Developing Health Status Index Using Factor Analysis," Journal of Fundamental and Applied
Sciences, 9(2S), hal. 82-92. doi: 10.4314/jfas.v9i2s.6.

Ramadhan, B. (2020) Air Minum Kemasan Galon Guna Ulang Masih Jadi Pilihan. Tersedia pada:

https://republika.co.id/berita/qbm8sl330/air -minum-kemasan-galon-guna-ulang-

masih-jadi-pilihan (Diakses: 18 Juni 2020).

Regina, T., Luin, J. A. dan Rembulan, G. D. (2020) "Mengurangi Keterlambatan Waktu Produksi Menggunakan Line Balancing pada Sektor Konstruksi Jalan Tol," in Prosiding Seminar Nasional Riset dan Teknologi. Jakarta: Universitas Indraprasta PGRI, hal. 258-263.

Rembulan, G. D. (2018) "Faktor-faktor yang Memengaruhi Getok Tular pada Usaha Restoran Waralaba di Jakarta," Jurnal Pengabdian dan Kewirausahaan, 2(1), hal. 17-28.

Rembulan, G. D. (2019) "Pengembangan Industri Kecil dan Menengah Tiwul Instan sebagai Alternatif Pendukung Ketahanan Pangan dalam Perspektif Konsumen," Industria: Jurnal Teknologi dan Manajemen Agroindustri, 8(2), hal. 87-94. doi: 10.21776/ub.industria.2019.008.02.2.

Rembulan, G. D. et al. (2020) "Optimalisasi Panjang Jaringan Pipa Air Bersih di DKI Jakarta Menggunakan Minimum Spanning Tree," Jurnal Intech, 6(1), hal. 75-87. doi: 10.30656/intech.v6i1.2164.

Rini, A. S. (2019) Investasi Industri Air Minum Kemasan Terus Tumbuh. Tersedia pada: https://ekonomi.bisnis.com/read/20190711/ 257/1123195/investasi-industri-air-minumkemasan-terus-tumbuh (Diakses: 18 Mei 2020).

Rowena, J., Wilujeng, F. R. dan Rembulan, G. D. (2020) "Pengaruh Kualitas Layanan dalam Menciptakan Kepuasan Publik di Kantor Pelayanan Publik, Jakarta Utara," Journal of Industrial Engineering and Management Systems, 13(1), hal. 27-34. doi: 10.30813/jiems.v13i1.2083.

Sachamanorom, W. dan Senoo, D. (2016) "Voice of the Customer Through Customer Cocreation: The Case of Fuji Xerox Japan," in Pacific Asia Conference on Information Systems, hal. 1-14. 
Saini, M., Kumar, A. dan Kaur, G. (2020) "Research Perception, Motivation and Attitude Among Undergraduate Students: A Factor Analysis Approach," Procedia Computer Science, 167, hal. 185-192. doi: 10.1016/j.procs.2020.03.210.

Sandi, F. (2020) 1,7 Juta Galon Air Masuk Jabodetabek/Hari, Bila Darurat Siap? Tersedia pada: https://www.cnbcindonesia.com/news/202 00331150739-4-148790/17-juta-galon-airmasuk-jabodetabek-hari-bila-darurat-siap (Diakses: 18 Mei 2020).

Sobhanifard, Y. (2018) "Hybrid Modelling of the Consumption of Organic Foods in Iran Using Explanatory Factor Analysis and An Artificial Neural Network," British Food Journal, 120(1), hal. 1-17.

Suwandi, E. (2016) "Penerapan Sistem Voice of Customer dalam Peningkatan Kualitas Produk Pie Susu pada Usaha Pie Elis," Jurnal Manajemen dan Start-Up Bisnis, 1(5), hal. 536-542.

Tannady, H. (2015) Pengendalian Kualitas. Yogyakarta: Graha Ilmu.

Utami, E. (2018) "Perancangan Desain Kemasan Produk Olahan Coklat 'Cokadol' dengan Metode Quality Function Deployment," Jurnal Integrasi Sistem Industri, 5(2), hal. 91-100.

Watson, J. C. (2017) "Establishing Evidence for Internal Structure Using Exploratory Factor Analysis," Measurement and Evaluation in Counseling and Development, 50(4), hal. 232-238. doi: 10.1080/07481756.2017.1336931.

Wilujeng, F. R. et al. (2019) "Meningkatkan Kepuasan Pelanggan pada Dua Bisnis E-
Commerce Terbesar di Indonesia dengan Menggunakan Analisis Servqual dan IPA," in Prosiding Seminar Nasional Sains dan Teknologi. Jakarta: Fakultas Teknik Universitas Muhammadiyah Jakarta, hal. $1-9$.

Wilujeng, F. R. dan Rembulan, G. D. (2019) "Perancangan Model Kualitas Pelayanan Puskesmas dengan Metode Importance Performance Analysis (IPA) dan Quality Function Deployment (QFD)," Jurnal Intech, 5(2), hal. 43-50. doi: 10.30656/intech.v5i2.1675.

Wilujeng, F. R., Rembulan, G. D. dan Regina, T. (2019) "Pengukuran Kualitas Layanan dengan Metode Service Quality pada Puskesmas Jakarta Utara," in Prosiding Seminar Nasional Teknik Industri. Lhokseumawe: Universitas Malikussaleh.

Wilujeng, F. R., Suyoto, Y. T. dan Rembulan, G. D. (2019) "Dampak Faktor Motivasi terhadap Performa Kerja Layanan Publik," in Prosiding Seminar Nasional Teknik Industri. Lhokseumawe: Universitas Malikussaleh, hal. 2-7.

Yustian, O. R. (2015) "Analisis Pengembangan Produk Berbasis Quality Function Deployment (QFD) (Studi Kasus pada Produk Susu PT. MSA)," Jurnal Ekonomi dan Bisnis, 18(3), hal. 23-42. doi: 10.24914/jeb.v18i3.279.

Zulkepli, M., Sipan, I. dan Jibril, J. D. (2017) “An Exploratory Factor Analysis and Reliability Analysis for Green Affordable Housing Criteria Instrument," International Journal of Real Estate Studies, 11(4), hal. 9-21. 